\title{
Comparing the Measured and Latent Dark Triad: Are Three Measures Better than One?
}

\author{
Peter K. Jonason \\ University of Western Sydney \\ Gregory D. Webster \\ University of Florida
}

\author{
Phillip S. Kavanagh \\ University of South Australia \\ Debra Fitzgerald \\ Central Queensland University
}

\begin{abstract}
Could measurement level be a factor worth considering when studying the Dark Triad (i.e., narcissism, psychopathy, and Machiavellianism)? In two studies $(N=465)$, we compared the relative fit of two Dark Triad models: one that treats the three measures as separate-yet-related personality traits and another that treats the measures as tapping a single, latent construct. Mid-level personality traits, such as mate-retention strategies (Study 1) were best explained by a three-measure model, whereas the higher-order trait of sociosexuality (Study 2), were best explained by a single, latent-factor model. When considering mid-level measurement in personality, the three traits may provide independent effects for interpersonal relationships, whereas at the higher-order level, the three traits may function as a single entity relating to other higher-order traits. We suggest one should consider level of measurement between the predictor and criterion variables to better predict correlations among variables such as the Dark Triad.
\end{abstract}

Keywords: Dark Triad, Structural Equation Modeling, Personality, Narcissism, Machiavellianism, Psychopath

There is little doubt that the Dark Triad traits represents three related, yet independent traits (Jonason, Li, Webster, \& Schmitt, 2009; Jones \& Paulhus, 2010; Lee \& Ashton, 2005; McHoskey, 1995; McHoskey, Worzel, \& Syzarto, 1995, Paulhus \& Williams, 2002). They appear to be linked by a core of disagreeableness (Paulhus \& Williams, 2002), lacking humility (Lee \& Ashton, 2005), a short-term (vs. long-term) mating orientation (Jonason et al., 2009), and feeling they can predict future outcomes (Jonason, Koenig, \& Tost, 2010). In contrast, the three traits are also differentially predictive of aspects of people's personality such as selfcontrol (Jonason \& Tost, 2010), risk-taking (Jonason et al., 2010a), strategic or impulsive social orientations (Jones \& Paulhus, 2010), a fast or opportunistic life strategy (Figueredo et al., 2006; Jonason, Koenig, \& Tost, 2010), mate-retention and mate-poaching (Jonason, Li, \& Buss, 2010), styles of love (Jonason \& Kavanagh, 2010), and aggressiveness (Jonason \& Webster, 2010). In this study we employ Structural Equation Modeling (SEM) to better understand how the Dark Triad traits predict mate-retention (Study 1) and sociosexuality (Study 2).

Modern conceptualizations of personality assume personality traits can be measured at a variety of levels (Jonason \& Webster, 2010; Markon, Krueger, \& Watson, 2005). For instance, the traditional five-factor model 
of personality (i.e., extraversion, agreeableness, conscientious, emotional stability, and openness) are mid-level traits (DeYoung, Peterson, \& Higgins, 2002; DeYoung, 2006; Digman, 1997; Hirsh, DeYoung, \& Peterson, 2009) that are predictive of a whole range of acts individuals may perform including mate-retention (Buss, 1998) and interpersonal manipulate (Buss, Gomes, Higgins, \& Lauterbach, 1987). Higher-order personality traits tend to reflect the shared variance of a number of these mid-level factors (DeYoung et al., 2002; Hirsch et al., 2009). Lower-order traits represent aspects of mid-level conceptualizations (DeYoung, Quilty, \& Peterson, 2007). We treat the Dark Triad traits as mid-level traits (i.e., 3 separate traits as traditionally assessed) and a single, composite trait (Jonason et al., 2009; Jonason \& Webster, 2010) in order to understand how the shared factor and the unique variance in the three traits predict sociosexuality and mate-retention.

Using this multilevel perspective on personality, we make one primary prediction. The best fit to data should happen when both variables are at the same level of measurement (i.e., a "matching hypothesis"). Sociosexuality (Simpson \& Gangestad, 1991) is a latent construct reflective of two (Webster \& Bryan, 2007) or three (Jackson \& Kirkpatrick, 2006; Penke \& Asendorpf, 2008) mid-level aspects. Therefore, we predict the common variance of the Dark Triad composite (Jonason et al., 2009; Jonason \& Webster, 2010) will provide a better fit to the data in explaining variance in sociosexuality than would the Dark Triad's three individual traits. Such a prediction is consistent with recent evidence assessing the relationship between sexual coercion and the Dark Triad where the common factor provided a better fit than the unique variance of the three traits (Sisco, Gladden, \& Figueredo, 2010).

Second, because the three traits may each assess slightly different aspects of a fast life strategy as suggested by much research (Figueredo et al., 2006; Jonason et al., 2009; Jonason \& Kavanagh, 2010; Jonason, Koenig, \& Tost, 2010; Jonason \& Tost, 2010; Jonason \& Webster, 2010), actual tactical-level personality assessments should be predicted more by the unshared variance of the three traits than the shared variance, in this case in the form of mate-retention tactics. Tactical-level traits may be midlevel traits like the Big Five, and, therefore, we expect the correlations with other mid-level variables-the actual Dark Triad traits and not the common factor-to better predict the tactical traits of mate-retention (i.e., intrasexual and intersexual manipulation).

In the present studies we present some initial testing of this "matching hypothesis" by using SEM to assess relative fit of two different models to account for variance in intersexual and intrasexual manipulation and sociosexuality. In so doing we hope to better ascertain the manner in which the Dark Triad independently and conjointly predicts aspects of people's life history strategies. We assess the correlations between the 
Dark Triad and mate-retention tactics and expect the unique variance provided by each trait will provide a better fit than the common factor (Study 1). Further, we assess the correlation between the Dark Triad and sociosexuality and expect the common factor to provide a better fit than the unique variances of each trait (Study 2). Essentially, we seek to address the question: "When are three traits better than one factor?"

\section{Study 1: Intrasexual and Intersexual Manipulation}

In Study 1 we reanalyze data on mate-retention (Jonason, Li, \& Buss, 2010). We use SEM to test which nested model fits the data best relative to a full model. Because mate-retention is a tactical-level set of personality traits, we expect the unique factor to have better fit indexes than a common Dark Triad factor.

\section{Method}

Participants. The participants in this study were used in a prior study (Jonason, Li, \& Buss, 2010). Volunteers $(N=336,66 \%$ female) from unique IP addresses recruited via Craigslist completed an online survey that informed them of the nature of the study, asked them demographic questions, and asked them to respond to the items described below. Upon completion, participants were thanked and debriefed.

Measures. Briefly, the Dark Triad was measured using the NPI (Raskin \& Terry, 1988), the Self-Report Psychopathy Scale-III (Paulhus, Neumann, \& Hare, in press), and the MACH-IV (Christie \& Geis, 1970). Items on the scale were aggregated into indexes (Cronbach's $\alpha=.87, .74$, .57 respectively). Tactics of mate-retention were averaged into the categories (Shackelford, Goetz, \& Buss, 2005) of Direct Guarding $(\alpha=.57)$, Intersexual Negative Inducements $(\alpha=.68)$, Positive Inducements $(\alpha=$ .75), Public Signals of Possession $(\alpha=.62)$, and Intrasexual Negative Inducement $(\alpha=.42)$. Although estimates are lower than one would hope, they are consistent with prior work (Shackelford et al., 2005). More details about these measures are provided in the original publication of the data (Jonason, Li, \& Buss, 2010).

\section{Results and Discussion}

Model testing. To compare the models, techniques described by Sisco, Gladden, \& Figueredo (2010) were employed. That is, the full models with both the contributions of the latent Dark Triad factor plus the unique contributions from the three Dark Triad traits as manifest indicators were run on inter- and intrasexual manipulation respectively. 
Intersexual selection. The full model examined the contributions of the latent Dark Triad factor plus the unique contributions from each of the three Dark Triad traits as manifest indicators (Figure 1). Equality constraints were used for the paths from psychopathy and Machiavellianism to the Dark Triad factor, with the pathway from direct guarding to intersexual manipulation fixed to 1.o. Adding constraints to the Psychopathy and Machiavellianism paths essentially split the contribution across these paths as previous testing had found these two

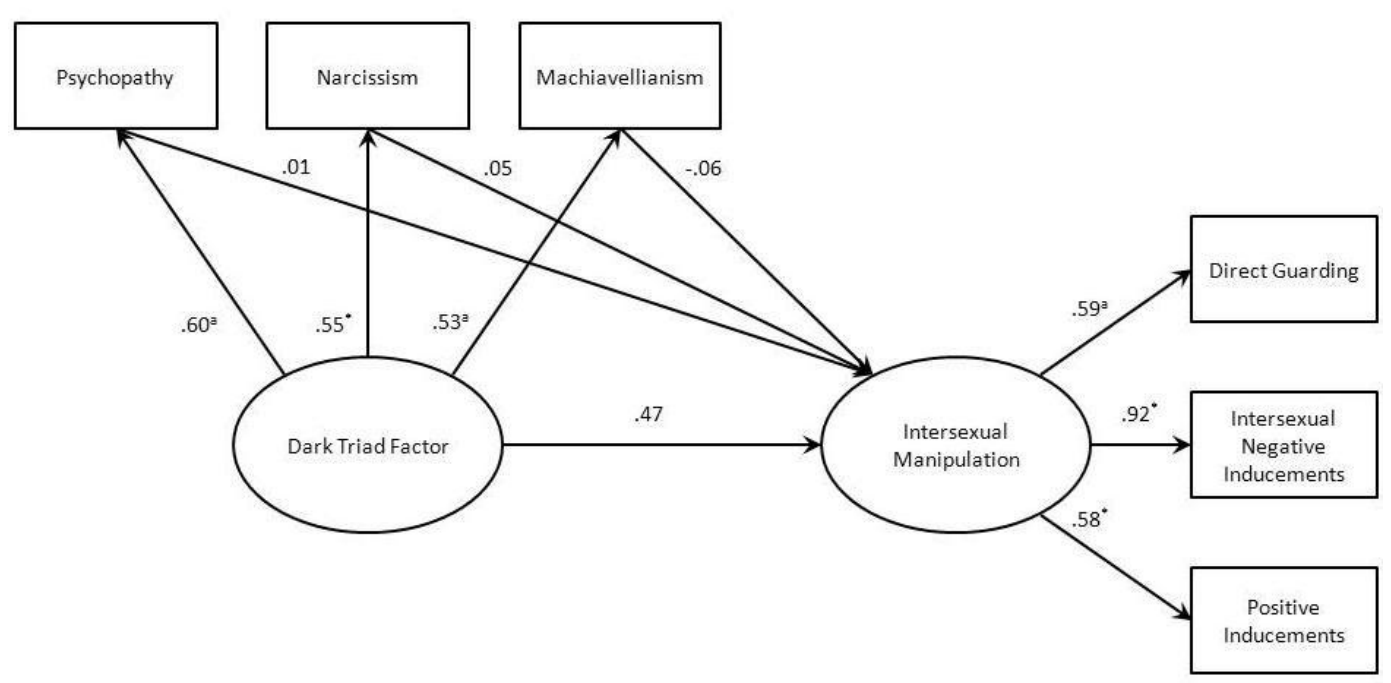

Figure 1: Common contribution from a latent Dark Triad factor plus the unique contributions from the three Dark Personality traits as manifest

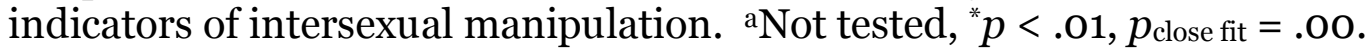

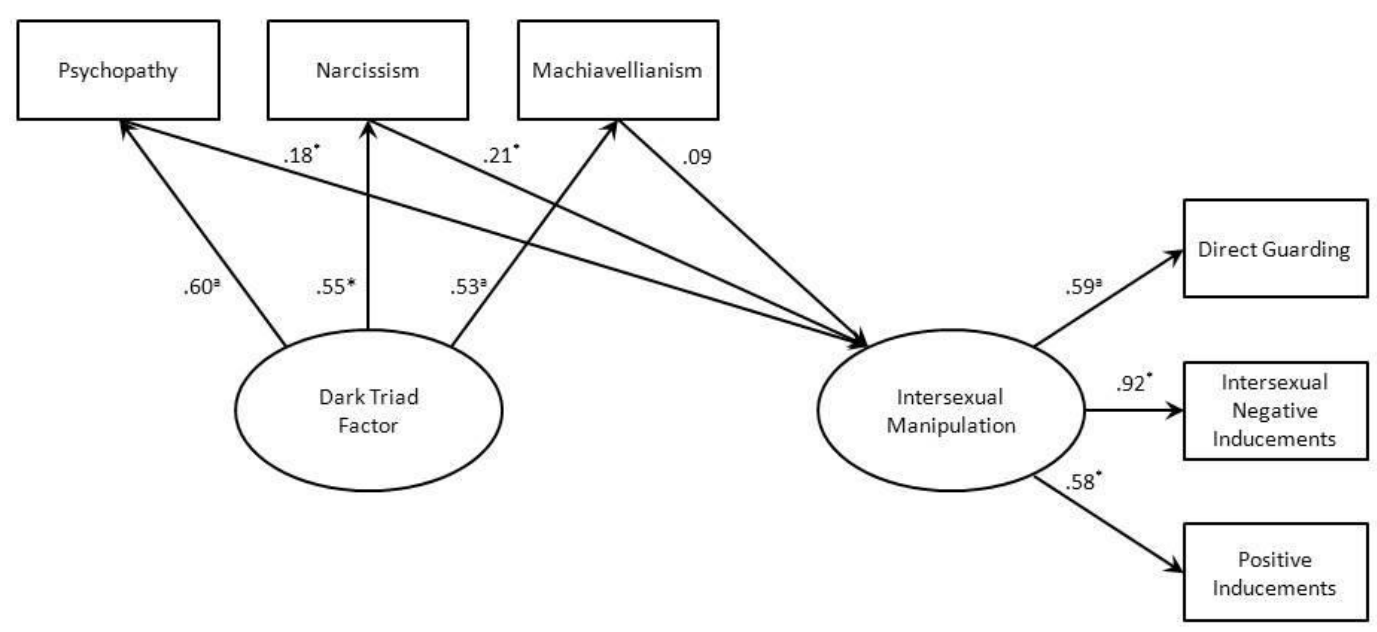

Figure 2: Unique contributions only from the three Dark Personality traits as manifest indicators of intersexual manipulation.

aNot tested, ${ }^{*} p<.01, p_{\text {close fit }}=.00$. 
paths to be the highest and lowest respectively. The second model estimated the unique contribution from the Dark Triad latent trait (Figure 2). The third model evaluated the contribution from the Dark Triad factor only (Figure 3).

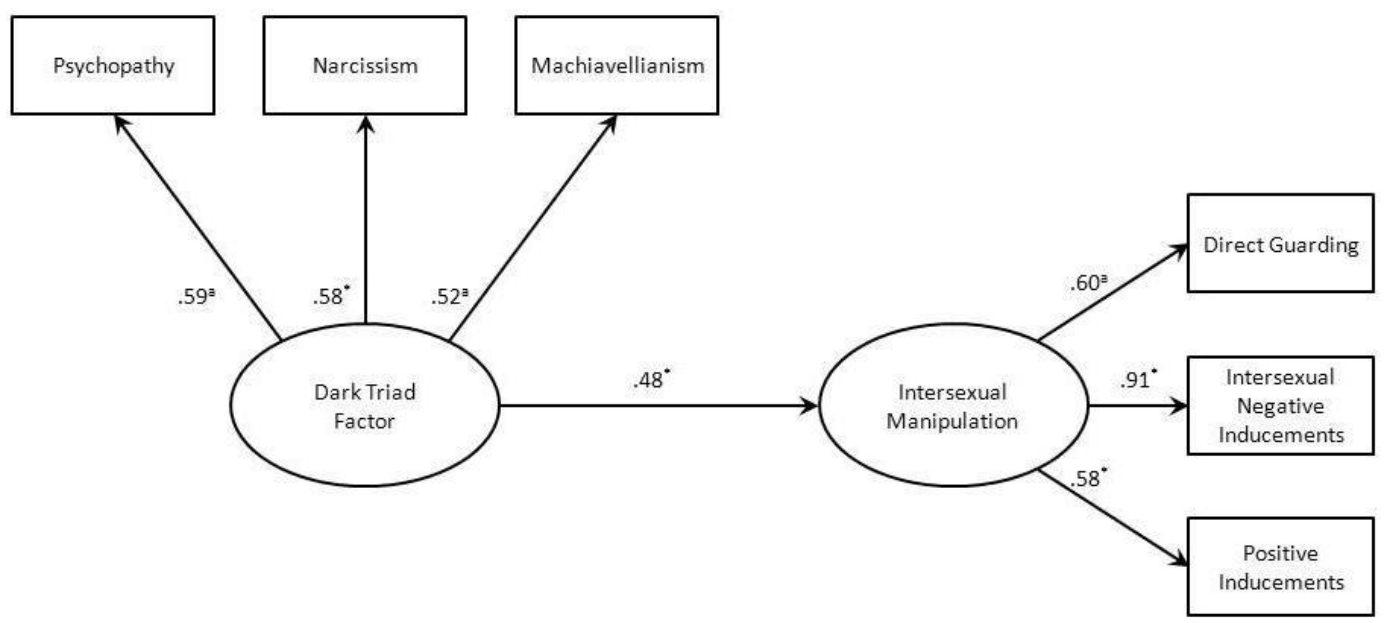

Figure 3: Common contribution only from the Dark Triad Factor of

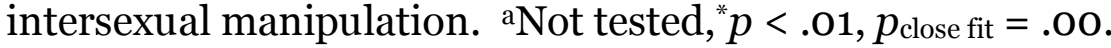

The results from the nested model comparisons for intersexual manipulation (Table 1) indicate the three-factor Dark Triad model fit the data slightly better than the single factor model.

Table 1

Nested model comparisons for common and unique contributions of the Dark Triad factor and Dark Personality traits on intersexual manipulation

\begin{tabular}{lcccccc}
\hline Model & $\chi^{2}$ & $d f$ & $N F I$ & $C F I$ & $\begin{array}{c}R M S E A \\
(90 \% \mathrm{CI})\end{array}$ & $\Delta \chi^{2}$ \\
\hline $\begin{array}{l}\text { 1. Observed \& latent } \\
\text { predictors }\end{array}$ & $50.36^{*}$ & 6 & .88 & .89 & $.14(.10, .17)$ & \\
$\begin{array}{l}\text { 2. Observed predictors } \\
\text { only }\end{array}$ & $50.36^{*}$ & 7 & .88 & .89 & $.14(.10, .17)$ & \\
$\quad \begin{array}{l}\text { Difference between } \\
\quad \text { Model 2 and Model 1 }\end{array}$ & & & & & & 0 \\
$\begin{array}{l}\text { 3. Latent predictors } \\
\text { only }\end{array}$ & $51.56^{*}$ & 9 & .88 & .89 & $.12(.09, .15)$ & \\
$\begin{array}{l}\text { Difference between } \\
\text { Model 3 and Model 1 }\end{array}$ & & & & & & 1.20 \\
${ }^{*} p<.01$ & & & & & & \\
\hline
\end{tabular}

Note $:$ NFI $=$ normed fit index; $\mathrm{CFI}=$ comparative fit index; RMSEA $=$ root-mean-square error of approximation 
Intrasexual selection. The same procedure was used to evaluate the contributions of the full model and unique contributions of the Dark Triad measures (Figures 4-6). Equality constraints were also used for public signs of possession and intrasexual negative inducements.

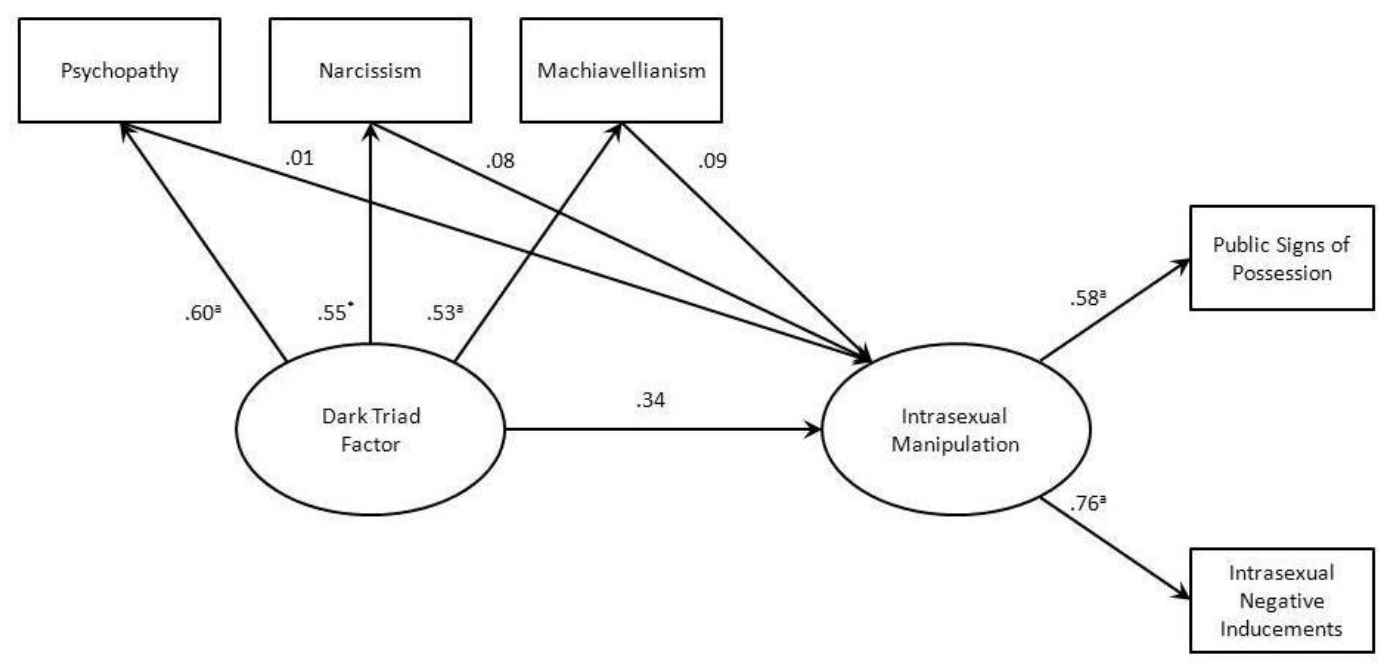

Figure 4: Common contribution from a latent Dark Triad factor plus the unique contributions from the three Dark Personality traits as manifest

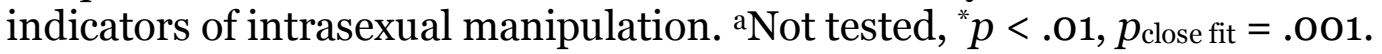

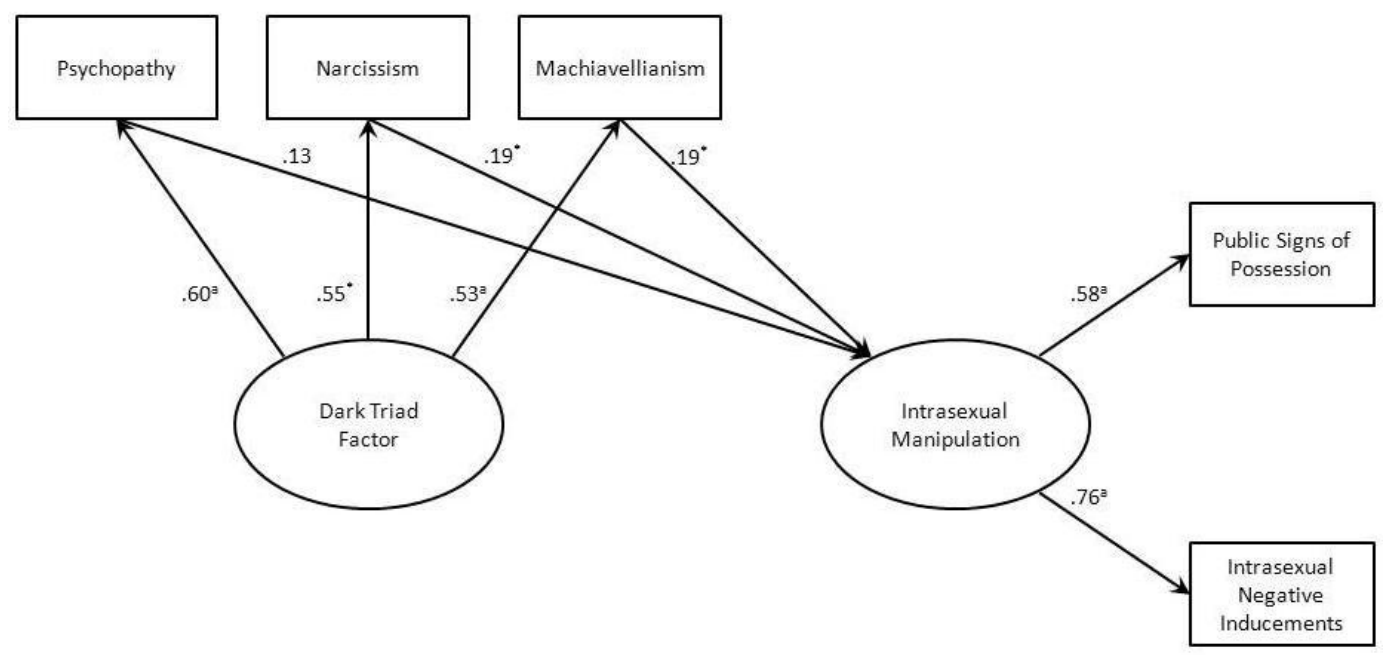

Figure 5: Unique contributions only from the three Dark Personality traits as manifest indicators of intrasexual manipulation. ${ }^{\text {NNot tested, }}$ ${ }^{*} p<.01, p_{\text {close fit }}=.00$. 


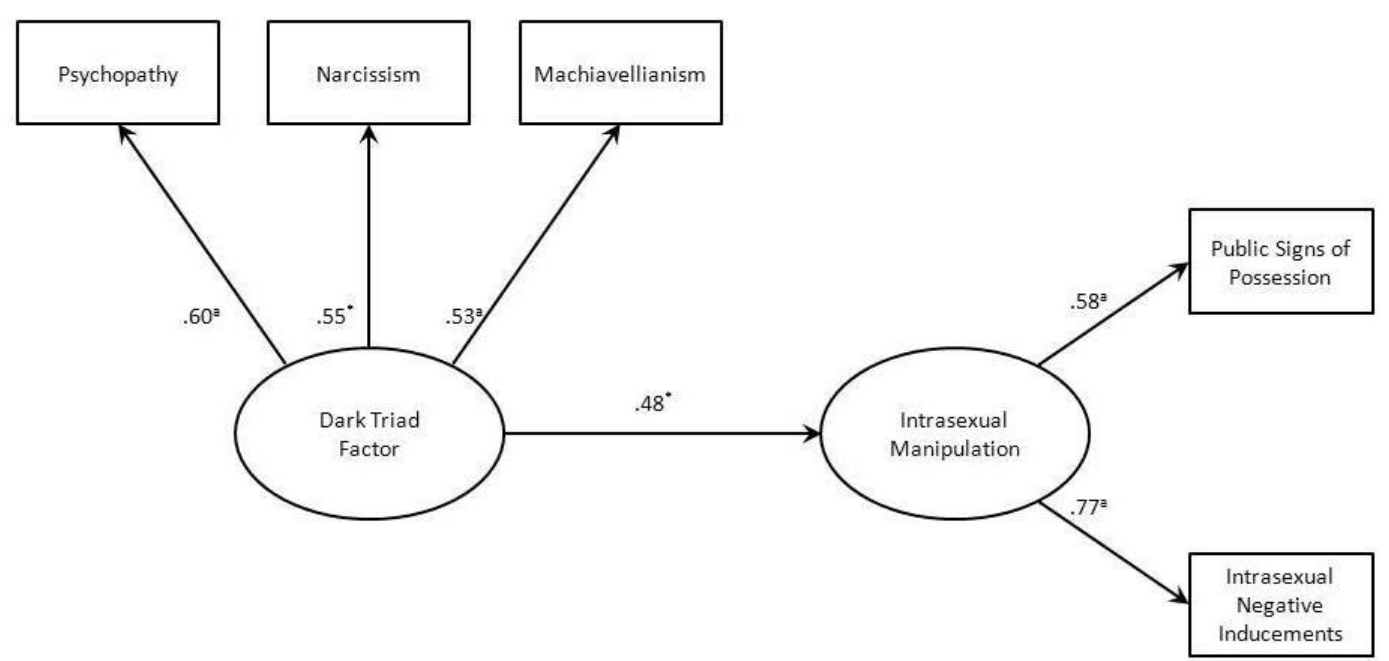

Figure 6: Common contribution only from the Dark Triad Factor of

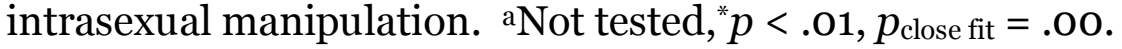

As with intersexual manipulation, the results for intrasexual manipulation also indicated a slightly better fit using the three-factor Dark Triad model. The results from this nested comparison are presented in Table 2.

Table 2 Nested model comparisons for common and unique contributions of the Dark Triad factor and Dark Personality traits on intrasexual manipulation

\begin{tabular}{lcccccc}
\hline Model & $\chi^{2}$ & $d f$ & $N F I$ & $C F I$ & $\begin{array}{c}R M S E A \\
(90 \% \mathrm{CI})\end{array}$ & $\Delta \chi^{2}$ \\
\hline $\begin{array}{l}\text { 4. Observed \& latent } \\
\text { predictors }\end{array}$ & $56.7 \mathrm{O}^{*}$ & 4 & .76 & .77 & $.20(.15, .25)$ & \\
$\begin{array}{l}\text { 5. Observed predictors } \\
\text { only }\end{array}$ & $56.70^{*}$ & 3 & .76 & .77 & $.20(.15, .25)$ & \\
$\quad \begin{array}{l}\text { Difference between } \\
\quad \text { Model 5 and Model 4 }\end{array}$ & & & & & & 0 \\
$\begin{array}{l}\text { 6. Latent predictors } \\
\text { only }\end{array}$ & $57.39^{*}$ & 6 & .76 & .77 & $.20(.12, .20)$ & \\
$\quad \begin{array}{l}\text { Difference between } \\
\quad \text { Model 6 and Model 4 }\end{array}$ & & & & & & 0.69 \\
${ }^{*} p<.01$ & & & & & & \\
\hline
\end{tabular}
Note $:$ NFI $=$ normed fit index; $\mathrm{CFI}=$ comparative fit index; RMSEA $=$ root-mean-square error of approximation 
In sum, the results indicate that the three Dark Triad measures make independent contributions to explaining variance in inter- and intrasexual manipulation that are not captured solely by a latent measure composed of the three Dark Triad measures. It seems to us that the lack of matching at the level of measurement may account for this effect. However, our lack of significant differences may be because intersexual and intrasexual manipulation, at the level we measured it is a mid-level trait. Greater conceptual distance may be needed to better test our predictions in the future. We report the correlation matrices in Appendix A and B.

\section{Study 2: Sociosexuality}

Next, we replicate prior work on the Dark Triad and sociosexuality (Jonason et al., 2009). Again, we compared relative fit using SEM. Because sociosexuality is itself a higher-order personality trait composed of lower order traits, we expect a common Dark Triad factor will fit the data better than a model that treats the Dark Triad as unique traits.

\section{Method}

Participants. Volunteers $(N=131,69 \%$ female) were recruited by email and through an Australian University's Psychology Department to complete an online survey that informed them of the nature of the study, asked them demographic questions, and asked them to respond to the items described below. Again, only those who participated from different IP addresses were included. Upon completion, participants were thanked and debriefed.

Measures. The Dark Triad was measured using the NPI-16 (Ames, Rose, \& Anderson, 2006), the Levenson Self-Report Psychopathy Scale (Levenson, Kiehl, \& Fitzpatrick, 1995), and the MACH-IV (Christie \& Geis, 1970). Items on these scales were aggregated into corresponding indexes (Cronbach's $\alpha=.65, .87, .77$ respectively).

Sociosexual orientation (SOI; Simpson \& Gangestad, 1991) was assessed, measuring both sociosexual attitudes and behaviors (Webster \& Bryan, 2007). Items were standardized before computing scores of SOI behaviors $(\alpha=.41)$ and SOI attitudes $(\alpha=.74)$ separately. Unfortunately, we found low levels of internal consistency; however, this was to be expected given so few items (Kline, 2000).

\section{Results and Discussion}

Model testing. We repeated the model testing we did in Study 1 (see Figures 7 to 9). Equality constraints were added to narcissism and Machiavellianism, and sociosexual attitudes and behaviors, with the path 
from Machiavellianism to sociosexual orientation set to 1.0 for the combine and unique contributions models.

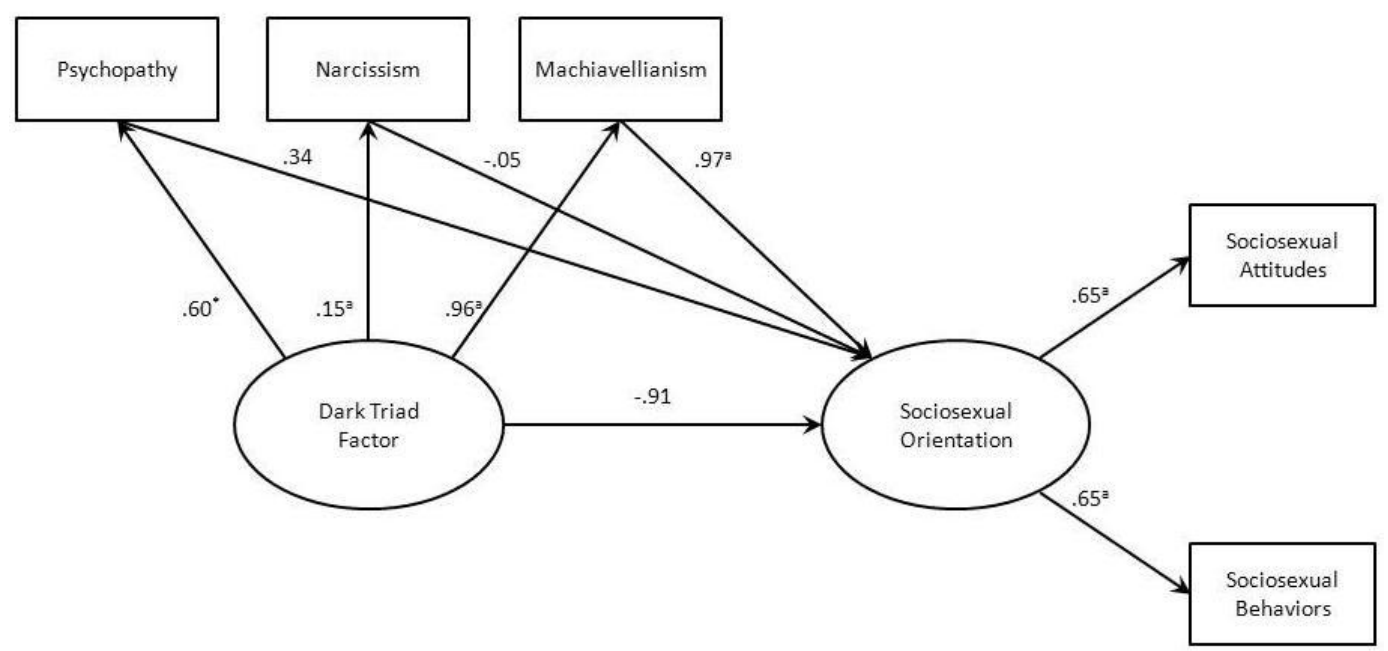

Figure 7: Common contribution from a latent Dark Triad factor plus the unique contributions from the three Dark Personality traits as manifest indicators of sociosexual orientation. ${ }^{\text {aNot tested. }}{ }^{*} p<.01, p_{\text {close fit }}=.00$.

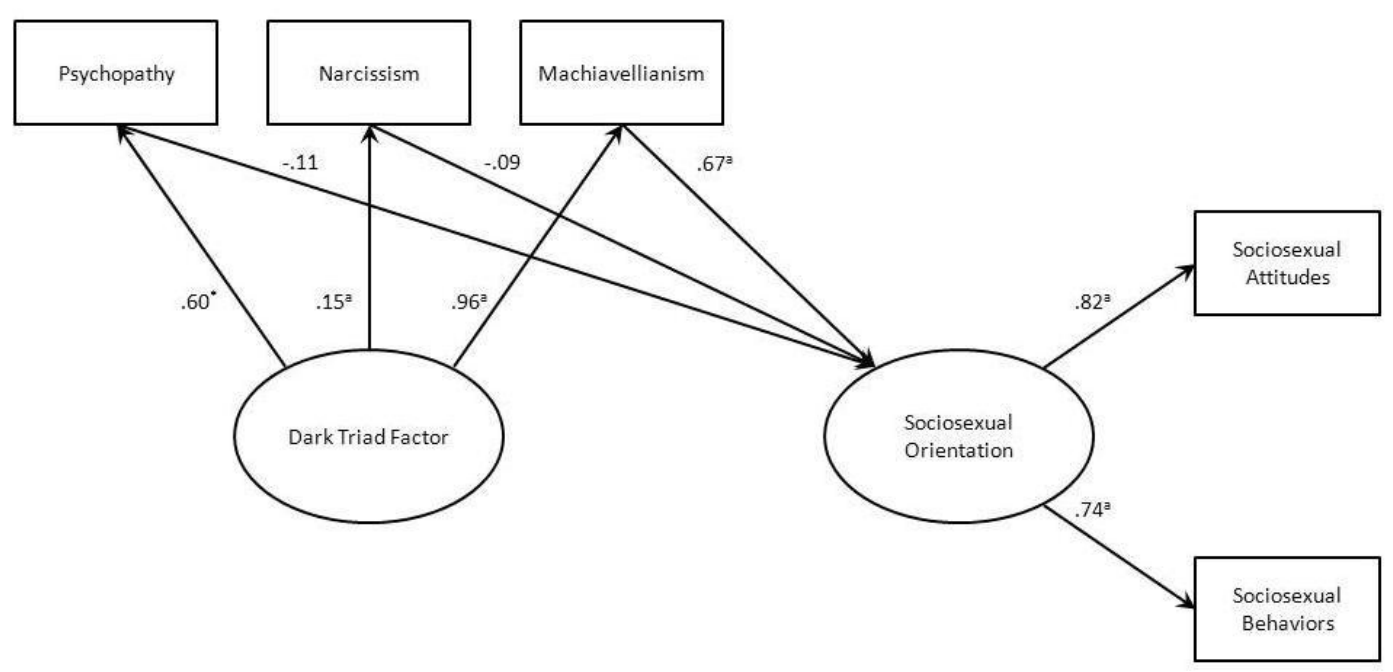

Figure 8: Unique contributions only from the three Dark Personality traits as manifest indicators of sociosexual orientation. aNot tested, ${ }^{*} p<.01, p_{\text {close fit }}=.00$. 


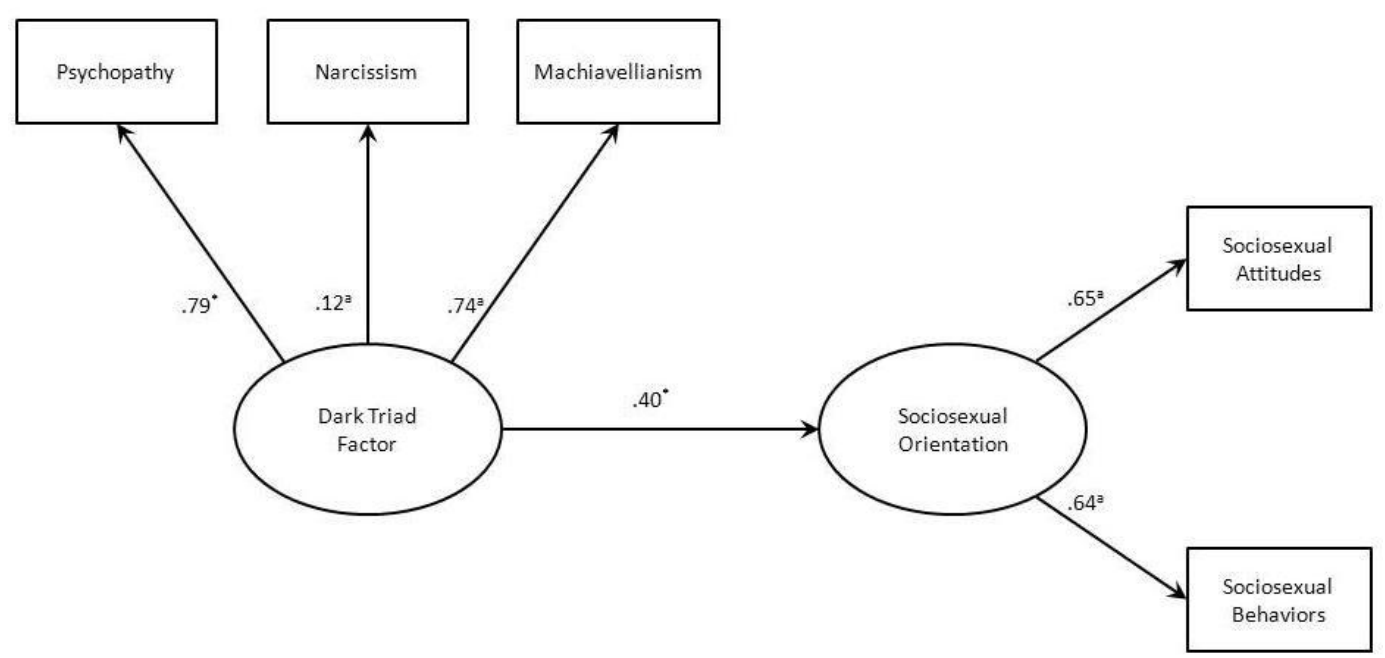

Figure 9: Common contribution only from the Dark Triad Factor of

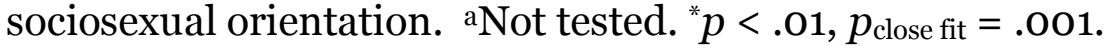

In contrast to the results in Study 1, the latent Dark Triad was superior to the measured Dark Triad model in accounting for variance in sociosexuality (see Table 3). This suggests the three Dark Triad measures are best correlated with sociosexuality through a latent factor rather than in an independent fashion. These results are consistent with our contention that higher-order personality traits correlate more strongly with the latent factor than lower-order factors. We report a correlation matrix in Appendix C.

Table 3

Nested model comparisons for common and unique contributions of the Dark Triad factor and Dark Personality traits on sociosexual orientation

\begin{tabular}{|c|c|c|c|c|c|c|}
\hline Model & $\chi^{2}$ & $d f$ & $N F I$ & CFI & $\begin{array}{c}\text { RMSEA } \\
(90 \% \mathrm{CI}) \\
\end{array}$ & $\Delta \chi^{2}$ \\
\hline $\begin{array}{l}\text { 7. Observed \& latent } \\
\text { predictors }\end{array}$ & $29.49^{*}$ & 4 & .78 & .79 & $.21(.14, .29)$ & \\
\hline $\begin{array}{l}\text { 8. Observed predictors } \\
\text { only }\end{array}$ & $58.10^{*}$ & 5 & .53 & .53 & $.29(.22, .35)$ & \\
\hline $\begin{array}{l}\text { Difference between } \\
\text { Model } 8 \text { and Model } 7\end{array}$ & & & & & & 28.61 \\
\hline $\begin{array}{l}\text { 9. Latent predictors } \\
\text { only }\end{array}$ & $28.69^{*}$ & 6 & .77 & .80 & $.17(.11, .24)$ & \\
\hline $\begin{array}{l}\text { Difference between } \\
\text { Model } 9 \text { and Model } 7\end{array}$ & & & & & & -0.81 \\
\hline
\end{tabular}
Note $:$ NFI = normed fit index; $\mathrm{CFI}=$ comparative fit index; RMSEA = root-mean-square error of approximation 


\section{General Discussion}

In order to provide some insight as to how measurement level affects correlations between the Dark Triad traits and other traits, we proposed and found that superior models are provided when the factors match on their measurement level. Tentatively, our moderated Structural Equation Models may also conform to our predictions. That is, when assessing one higher-order trait (i.e., sociosexuality), the common factor of the Dark Triad fit the data better, but when assessing mid-level traits (i.e., mate retention), the individual traits were superior (albeit slightly). We would argue this has implications for measurement in the social sciences but also in the debate among Dark Triad researchers as two the best way to measure the Dark Triad.

Personality traits tend to reflect latent dispositions or behavioral regularities. When they represent latent dispositions, they tend to tap into people's deeper dispositional approaches to life. Both Sociosexuality and the Dark Triad represent higher-order personality traits that are reflective of midlevel dispositions. For instance, the Dark Triad creates a short-term psychology (e.g., Jonason et al., 2010a) at the latent, higher-order level that is partially reflected in midlevel traits like psychopathy. Lower-order traits that reflect behavioral regularities like tactical styles for materetention likely correlate with higher-order traits as a byproduct of tapping into related psychologies (and error in measurement). However, our results suggest researchers should be weary of correlating variables at differing levels of measurement. Although this consideration may not be particularly relevant to exploratory and psychometric studies, researchers doing theoretical studies should take caution in over-interpreting correlations among variables that do not match in their levels of measurement.

Effectively, there are two main schools of thought about the Dark Triad. Both schools treat the three as separate-yet-related traits but disagree on the utility of a single-latent factor. Work highlighting the divergent interpersonal outcomes suggests each trait is not related to the same aspects of the Big Five, aggression, and strategic-mindedness (Jones \& Paulhus, 2010; Paulhus \& Williams, 2002). The divergent nature of the Dark Triad is not contested by the other group; the other group simply takes a hierarchical approach to the Dark Triad, suggesting they may conjointly predict variability in human behavior and it is this latent disposition that is more likely to have been selected by evolutionary forces rather than selection tailoring the three traits independently (Jonason et al., 2009; Jonason \& Webster, 2010). Prior work confirms this latter contention with sexual coercion (Sisco, Gladden, \& Figueredo, 2010) and the present study further tests and confirms this assertion. We add, 
however, that the reason this discrepancy occurs has to do with the level of measurement in the variables under consideration.

There were at least four noteworthy limitations. First, the sample size in Study 2 was on the small side; ideally one wants a sample of at least 200 for SEM because samples of that size tend to show less sampling error (Bollen \& Long, 1993). In Study 1, because we reanalyzed data that was already published it would be in error to collect more data and add this to the old dataset. In the case of Study 2, data was collected as part of the fourth author's Master's thesis and is archival data at this point.

The second limitation-one that may be related to the first-is that narcissism, as measured by the 16-item NPI-16, was not related to sociosexuality, whereas the 40-item NPI has been shown to be related to sociosexuality (Jonason et al., 2009; Jonason \& Webster, 2010). This lack of correlation may be because the NPI-16 taps the authority dimension of narcissism, which may not be related to mating orientations (Joshua Foster, 2010, personal communication). Indeed, the measures of narcissism and psychopathy used in Study 2 have rarely been used in Dark Triad research, and this may limit our ability to generalize across our studies. However, this may be a strength of this paper because we attempted to expand the research on the Dark Triad to include more measures of its three traits. Nevertheless, we were able to replicate associations between an alternative measure of psychopathy along with the traditional measure of Machiavellianism and its correlation with sociosexuality. The correlation between narcissism and sociosexuality was weak, although it was in the expected direction.

Third, past research suggests men and women reliably differ on the Dark Triad traits (Jonason et al., 2009; Jonason \& Webster, 2010). Given the small sample sizes any SEM tests moderated by the sex of the participant would likely suffer intolerable levels of standard error and therefore, any analyses done would not be trustworthy. Future research should ascertain if considering sex-specific models provide even better fit indices. We would predict that the better fits would be found in men at the higher-order level but no sex differences at lower-order levels.

Fourth, some of our outcome variables had low levels of internal consistency. In the case of sociosexual behaviors and intrasexual negative inducement, the Cronbach's alphas fell below both the traditional, restrictive cutoffs of .70 (Nunnally, 1978) and the more liberal standards of .50 (Schmitt, 1996). The remaining estimates returned acceptable-tomoderate rates of internal consistency $(>.50 ;<.80)$. Not only should we expect such low alphas as a result of each scale being composed of so few items-because of the positive relationship between number of items and alpha (Carmines \& Zeller, 1979)-but also because Cronbach's alpha assumes unidimensionality where it might not exist (Zinbarg, Revelle, Yovel, \& Li, 2005). Alpha might be overly restrictive and provide 
potentially biased estimates of internal consistency (Zinbarg, Yovel, Revelle, \& McDonald, 2006). Nevertheless, further work is required to verify our hypothesis with more detailed, lengthy, and reliable personality measures. Despite these limitations, our findings were consistent with our predictions.

Although these studies only provide one test of our prediction, we believe that our results may generalize to other tests of higher- and lowerorder personality traits. To date, most work on the Dark Triad has examined its relationships with lower-order constructs. For instance, correlating the Dark Triad with mate-poaching, mate-retention (Jonason et al., 2010b), and self-control (Jonason \& Tost, 2010) has examined the relationship between the Dark Triad and behavioral regularities. We encourage future work examining the correlation between the Dark Triad and higher-order personality traits, by either using multiple indicators of latent dispositions such as work in Life History Theory (Figueredo et al., 2006), or by examining meta-traits such as Plasticity or Stability (DeYoung, 2006; DeYoung et al., 2002).

We investigated whether the three measured Dark Triad traits were better than one latent Dark Triad factor in predicting sociosexuality and mate-retention tactics. Like so many phenomena in psychology, the short answer is: "It depends." In this case, the answer depends on the level of the outcome variable. According to our findings, if the outcome variable is a mid- or lower-order trait, then three factors are better than one. If the outcome variable is higher-order, then one factor is better than three. In closing, we have offered a "level-matching model" for how to conceive of the structural relations among personality traits related to the Dark Triad.

Corresponding author: Peter K. Jonason, School of Psychology, University of Western Sydney, Locked Bag 1797, Penrith NSW 2751, Australia, email: peterkarljonason@yahoo.com

\section{References}

Ames, D. R., Rose, P., \& Anderson, C. P. (2006). The NPI-16 as a short measure of narcissism. Journal of Research in Personality, 40, 440-450.

Bollen, K. A., \& Long, J. S. (Eds) (1993). Testing structural equation models. Newbury Park, CA: Sage.

Buss, D. M. (1988). From Vigilance to Violence: Tactics of mate retention in American undergraduates. Ethology \& Sociobiology, 9, 291-317.

Buss, D. M., Gomes, M., Higgins, D. S., \& Lauterbach, K. (1987). Tactics of manipulation. Journal of Personality and Social Psychology, 52, 1219-1229.

Carmines, E. G., \& Zeller, R. A. (1979). Reliability and validity assessment: Quantitative applications in the social sciences series (Vol. 17). Newbury Park, CA: Sage. 
Christie, R., \& Geis, F. L. (1970). Studies in Machiavellianism. New York: Academic Press.

DeYoung, C. G. (2006). Higher-order factors of the Big Five in a multi-informant sample. Journal of Personality and Social Psychology, 91, 1138-1151.

DeYoung, C. G., Peterson, J. B., \& Higgins, D. M. (2002). Higher-order factors of the Big Five predict conformity: Are there neuroses of health? Personality and Individual Differences, 33, 533-552.

DeYoung, C. G., Quilty, L. C., \& Peterson, J. B. (2007). Between facets and domains: 10 aspects of the Big Five. Journal of Personality and Social Psychology, 93, 880-896.

Digman, J. M. (1997). Higher-order factors of the Big Five. Journal of Personality and Social Psychology, 73, 1246-1256.

Figueredo, A. J., Vásquez, G., Brumbach, B. H., Schneider, S. M. R., Sefcek, J. A., Tal, I. R., Hill, D., Wenner, C. J., \& Jacobs, W. J. (2006). Consilience and Life History Theory: From genes to brain to reproductive strategy. Developmental Review, 26, 243-275.

Hirsh, J. B., DeYoung, C. G., \& Peterson, J. B. (2009). Metatraits of the Big Five differentially predict engagement and restraint of behavior. Journal of Personality, 77, 1085-1102.

Jackson, J. J., \& Kirkpatrick, L. A. (2006). The structure and measurement of human mating strategies: Toward a multidimensional model of sociosexuality. Evolution and Human Behavior, 28, 382-391.

Jonason, P. K., \& Kavanagh, P. (2010). The dark side of love: The Dark Triad and love styles. Personality and Individual Differences, 49, 606-610.

Jonason, P. K., Koenig, B., \& Tost, J. (2010a). Living a fast life: The Dark Triad and Life History Theory. Human Nature, 21, 428-442.

Jonason, P. K., Li, N. P., \& Buss, D. M. (2010b). The costs and benefits of the Dark Triad: Implications for mate poaching and mate retention tactics. Personality and Individual Differences, 48, 373-378.

Jonason, P. K., Li, N. P., Webster, G. W., Schmitt, D. P. (2009). The Dark Triad: Facilitating short-term mating in men. European Journal of Personality, 23, 5-18.

Jonason, P. K., \& Tost, J. (2010). I just cannot control myself: The Dark Triad and self-control. Personality and Individual Differences, 49, 611-615.

Jonason, P. K., \& Webster, G. D. (2010). The Dirty Dozen: A concise measure of the Dark Triad. Psychological Assessment, 22, 420-432.

Jones, D. N., \& Paulhus, D. L. (2010). Different provocations trigger aggression in narcissists and psychopaths. Social Psychological and Personality Science, 1, 12-18.

Kline, P. (2000). The handbook of psychological testing (2nd ed.). London, England: Routledge.

Lee, K., \& Ashton, M. C., (2005). Psychopathy, Machiavellianism, and Narcissism in the Five-Factor Model and the HEXACO model of personality structure. Personality and Individual Differences, 38, 1571-1582.

Levenson, M. R., Kiehl, K. A., \& Fitzpatrick, C. M. (1995). Assessing psychopathic attributes in a noninstitutionalized population. Journal of Personality and Social Psychology, 68, 151-158. 
Markon, K. E., Krueger, R. F., \& Watson, D. (2005). Delineating the structure of normal and abnormal personality: An integrative hierarchical approach. Journal of Personality and Social Psychology, 88, 139-157.

McHoskey, J. (1995). Narcissism and Machiavellianism. Psychological Reports, 77, 755-759.

McHoskey, J., Worzel, W., \& Syzarto, C. (1995). Machiavellianism and psychopathy. Journal of Personality and Social Psychology, 74, 192-210.

Nunnally, J.C. (1978). Psychometric theory (2 ${ }^{\text {nd }}$ ed). New York: McGraw Hill.

Paulhus, D. L., Neumann, C. S., \& Hare, R. (in press). Manual for the self-report psychopathy scale (SRP). Toronto: Multi-Heath Systems.

Paulhus, D. L., \& Williams, K. M. (2002). The dark triad of personality: Narcissism, Machiavellianism, and psychopathy. Journal of Research in Personality, 36, 556-563.

Penke, L., \& Asendorpf, J. B. (2008). Beyond global sociosexual orientations: A more differentiated look at sociosexuality and its effects on courtship and romantic relationships. Journal of Personality and Social Psychology, 95, 1113-1135.

Raskin, R. N., \& Terry, H. (1988). A principal components analysis of the Narcissistic Personality Inventory and further evidence of its construct validity. Journal of Personality and Social Psychology, 54, 890-902.

Schmitt, N. (1996). Uses and abuses of coefficient alphas. Psychological Assessment, 8, 350-353.

Shackelford, T. K., Goetz, A. T., \& Buss, D. M. (2005). Mate retention in marriage: Further evidence of the reliability of the Mate Retention Inventory. Personality and Individual Differences, 39, 415-425.

Simpson, J., \& Gangestad, S. (1991). Individual differences in sociosexuality: Evidence for convergent and discriminant validity. Journal of Personality and Social Psychology, 6o, 870-883.

Sisco, M. M., Gladden, P. R., \& Figueredo, A. J. (2010). Sexual coercion and the Dark Triad. Talk presented at the Human Behavior and Evolution Society meeting in Eugene, OR.

Zinbarg, R. E., Revelle, W., Yovel, I., \& Li, W. (2005). Cronbach's $\alpha$, Revelle's $\beta$, and McDonald's $\left.\omega_{H}\right)$ : Their relations with each other and two alternative conceptualizations of reliability. Psychometrika, 7O, 123-133.

Zinbarg, R. E., Yovel, I., Revelle, W., \&McDonald, R. P. (2006). Estimating generalizability to a latent variable common to all of a scale's indicators: A comparison of estimators for $\omega_{H}$. Applied Psychological Measurement, 30, 121-144.

Webster, G. D., \& Bryan, A. (2007). Sociosexual attitudes and behaviors: Why two factors are better than one. Journal of Research in Personality, 41, 917922. 


\section{Appendix A}

Correlations between the Dark Triad Traits, the Latent Dark Triad, and Intersexual Mate-retention

\begin{tabular}{|c|c|c|c|c|c|c|c|c|}
\hline & 1 & 2 & 3 & 4 & 5 & 6 & 7 & 8 \\
\hline 1. Machiavellianism & - & & & & & & & \\
\hline 2. Psychopathy & $.31^{* *}$ & - & & & & & & \\
\hline 3. Narcissism & .08 & $.48^{* *}$ & - & & & & & \\
\hline $\begin{array}{l}\text { 4. Dark Triad } \\
\text { composite }\end{array}$ & $.63^{* * *}$ & $.82^{* * *}$ & $.72^{* *}$ & - & & & & \\
\hline $\begin{array}{l}\text { 5. Intersexual mate- } \\
\text { retention composite }\end{array}$ & $.18^{* *}$ & $.27^{* *}$ & $.26^{* *}$ & $.33^{* *}$ & - & & & \\
\hline 6. Direct guarding & $.15^{* *}$ & $.19^{* * *}$ & $.12^{*}$ & $.21^{* *}$ & $.76^{* * *}$ & - & & \\
\hline $\begin{array}{l}\text { 7. Intersexual negative } \\
\text { inducements }\end{array}$ & $.13^{*}$ & $.29^{* * *}$ & $.28^{* *}$ & $.32^{* * *}$ & $.88^{* * *}$ & $.55^{* *}$ & - & \\
\hline $\begin{array}{l}\text { 8. Positive } \\
\text { inducements }\end{array}$ & $.17^{* *}$ & $.17^{* * *}$ & $.21^{* * *}$ & $.25^{* * *}$ & $.78^{* *}$ & $.34^{* * *}$ & $.53^{* * *}$ & - \\
\hline $\mathrm{M}$ & 2.57 & 2.11 & 17.34 & 0.01 & 2.09 & 1.69 & 2.10 & 2.49 \\
\hline SD & 0.38 & 0.38 & 7.52 & 0.72 & 0.46 & 0.50 & 0.64 & 0.57 \\
\hline
\end{tabular}

Appendix B

Correlations between the Dark Triad Traits, the Latent Dark Triad, and Intrasexual Mate-retention

\begin{tabular}{|c|c|c|c|c|c|c|c|}
\hline & 1 & 2 & 3 & 4 & 5 & 6 & 7 \\
\hline 1. Machiavellianism & - & & & & & & \\
\hline 2. Psychopathy & $.31^{* * *}$ & - & & & & & \\
\hline 3. Narcissism & .08 & $.48^{* *}$ & - & & & & \\
\hline $\begin{array}{l}\text { 4. Dark Triad } \\
\text { composite }\end{array}$ & $.63^{* * *}$ & $.82^{* * *}$ & $.72^{* * *}$ & - & & & \\
\hline $\begin{array}{l}\text { 5. Public signals of } \\
\text { possession }\end{array}$ & $.19^{* * *}$ & .08 & .06 & $.14^{*}$ & - & & \\
\hline $\begin{array}{l}\text { 6. Intrasexual negative } \\
\text { inducements }\end{array}$ & $.16^{* *}$ & $.27^{* * *}$ & $.25^{* *}$ & $\cdot 31^{* *}$ & $.43^{* * *}$ & - & \\
\hline $\begin{array}{l}\text { 7. Intrasexual mate- } \\
\text { retention composite }\end{array}$ & $.21^{* *}$ & $.17^{* *}$ & $.17^{* *}$ & $.25^{* * *}$ & $.89^{* *}$ & $.80^{* * *}$ & - \\
\hline $\mathrm{M}$ & 2.57 & 2.11 & 17.34 & 0.01 & 2.39 & 1.58 & 1.99 \\
\hline SD & 0.38 & 0.38 & $7 \cdot 52$ & 0.72 & 0.67 & 0.52 & 0.51 \\
\hline
\end{tabular}


JONASON ET AL.

\section{Appendix C}

Correlations between the Dark Triad Traits, the Latent

Dark Triad, and Sociosexuality

\begin{tabular}{|c|c|c|c|c|c|c|c|}
\hline & 1 & 2 & 3 & 4 & 5 & 6 & 7 \\
\hline 1. Narcissism & - & & & & & & \\
\hline 2. Machiavellianism & $.31^{* *}$ & - & & & & & \\
\hline 3. Psychopathy & $.38^{* * *}$ & $.57^{* *}$ & - & & & & \\
\hline $\begin{array}{l}\text { 4. Dark Triad } \\
\text { composite }\end{array}$ & $.72^{* *}$ & $.80^{* * *}$ & $.83^{* * *}$ & - & & & \\
\hline 5. Sociosexuality Index & .07 & $.27^{* *}$ & $.24^{* *}$ & $.25^{* * *}$ & - & & \\
\hline $\begin{array}{l}\text { 6. Sociosexual } \\
\text { Behaviors }\end{array}$ & .01 & .01 & $.18^{*}$ & .09 & $.67^{* *}$ & - & \\
\hline $\begin{array}{l}\text { 7. Sociosexual } \\
\text { Attitudes }\end{array}$ & .01 & $.33^{* *}$ & $.24^{* * *}$ & $.29^{* * *}$ & $.93^{* * *}$ & $.42^{* * *}$ & - \\
\hline$M$ & 4.20 & 2.75 & 2.20 & 0.00 & 0.00 & 0.00 & 0.00 \\
\hline SD & 2.76 & 0.43 & 0.47 & 0.78 & 0.59 & 0.68 & 0.70 \\
\hline
\end{tabular}

